\section{Influence of Site on Mesquite Mortality from 2,4,5-T}

\section{B. E. DAHL, R. B. WADLEY, M. R. GEORGE,} AND J. L. TALBOT

Associate Professor, Research Associate, and Graduate Research Assistants, Department of Range and Wildlife Management, Texas Tech University, Lubbock.

\section{Highlight}

Soil temperature at the 18-inch depth was the most important factor affecting response of honey mesquite to 2,4,5-T application. Temperatures at this depth in the high 60's $F$ or low 70's $F$ resulted in no mesquite kills with the best results obtained if temperatures were over $80 \mathrm{~F}$. Phenological development was essentially as important with plants having mature leaves and seed pods being easiest to kill. Trees with small and blooming spikes and those without flowers or pods were hardest to kill with 2,4,5-T. Other variables usually considered important, such as soil moisture, were important only in combination with other variables. Mesquite trees growing on upland and sandy sites are apparently more susceptible to 2,4,5-T largely because the soil is usually several degrees $F$ warmer than bottomland and clay sites.

Because the translocation of growth regulating herbicides is closely associated with the translocation of organic food materials, any environmental factor such as temperature, light, water, and nutrients that influence translocation of organic food materials would probably influence translocation of systemic herbicides (Tingey et al., 1967). Thus, the response of plants to a herbicide may be quite different if the plants are growing under different environmental conditions. This is precisely the conclusion of Fisher et al. (1959). They obtained more cffective mesquite control in almost all tests when 2,4,5-trichlorophenoxyacetic acid (2,4,5-T) was applied to trees growing on sandy soils or on upland sites. Mesquite kills were consistently $20 \%$ less if growing on clay or clay loam bottomland sites. $\Lambda$ major objective of this study was to try to isolate the reasons why site differences influence

\footnotetext{
${ }^{1}$ Received April 11, 1970; accepted for publication November 5,1970 .
}

herbicidal kills of honey mesquite (Prosopis glandulosa var. glandulosa).

\section{Literature Review}

Herbicidal applications to mesquite in Texas, Arizona, and New Mexico indicate that low-volatile esters of 2,4,5,-T are more effective and less hazardous than many other closely related systemic chemicals (Fisher et al., 1959; Tschirley and Hull, 1959). More recently, field trials (Robison et al., 1970) with a mixture of picloram and 2,4,5-T indicate that this mixture can considerably increase degree of control of mesquite as compared to 2,4,5-T alone. Regardless, it is known that the effectiveness of all systemic herbicides is conditioned by environmental and other factors that prevail at the time of application (Freed and Morris, 1967).

Both Texas and Arizona researchers agree that despite its limitations, stage of growth is the best single method for determining maximum susceptibility of mesquite to foliage sprays. At Spur, Texas, the optimum treatment date is approximately 65 days after the first leaves appear in the spring. Apparently, this is during the time when the carbohydrate content of the roots is being replenished and 10 to 15 days after the leaves are fully formed and turn from light to dark green (Fisher et al., 1959). Tschirley and Hull (1959) identify this period in Arizona as that time when the leaves have reached full size but are still succulent, flower development is complete, and pods have formed but are less than 1 inch long. In both states, this period of optimum growth stage may occur anytime from about mid-May to mid-July. Also, Crafts (1953), Barrier and Loomis (1957), and numerous others have found maximum transport of 2,4-D and 2,4,5-T when the plants were actively accumulating reserves.

While adequate soil moisture to prevent moisture stress within growing plants is generally believed desirable for the best control of plants with growth regulating herbicides, its importance in the hcrbicidal control of mcsquitc is still in doubt. Mesquite control in Texas is seemingly correlated with degrees of available soil moisture (Fisher et al., 1956; Fisher et al., 1959). However, Cox (1952) concluded that soil moisture did not have a significant effect on the longterm toxicity of phenoxy herbicides when applied to velvet mesquite (Prosopis velutina) in Arizona. Basler et al. (1961) demonstrated that relative turgidity of leaf tissue was a good indicator of the ability of bean plants to translocate 2,4-D. But, Tschirley and Hull (1959) could find no correlation with percentage leaf moisture in velvet mesquite and herbicidal effectiveness. Of interest, however, is that the correlation coefficient was much closer to being 
significant with the amine than with the ester formulation of 2,4,5-T.

Probably the most neglected environmental characteristic affecting translocation within a plant is temperature. Temperature is known to have complex effects on plants and slight differences in temperature at critical periods may cause large differences in final growth responses, including flowering. The onset of flowering appears especially critical to a plant's response to chemicals. Also, temperature not only affects absorption and translocation but simultaneously alters the sensitivity of the plant to external stimuli (Muzik, 1967).

Muzik (1967) was able to demonstrate that Amsinkia intermedia plants grown at temperatures cool enough to reduce their growth rate either failed to respond to 2,4-D or responded much less than those plants grown at higher temperatures. However, when they were sprayed with a solution containing a metabolite, such as thiamin, which would increase growth at this temperature, the response to 2,4-D was markedly increased. He concluded that this lack of response to 2,4-D at low temperature was caused by a temperature induced shortage of thiamin rather than the reduction of 2,4-D entry and translocation per se. Tingey et al. (1967) found that a $100 \mathrm{~F}(37.5 \mathrm{C})$ environment considerably enhanced 2,4-D damage to Canada thistle roots compared to similar plants grown in a $65 \mathrm{~F}$ (18.5 C) environment.

Adding to the complexity of a plant's response to temperature are the separate responses of leaf, stem, petiole, and root to changing temperatures. At low temperatures, the consumption of sugars in the root is slowed more than translocation to the root. Hence, sugars accumulate in the root deterring further transport to that organ. On the contrary, sugars are rapidly used in the respiration of both root and leaf at high temperatures and the leaf has but little material to export. Also, low temperatures applied to local areas on the stem or petiole greatly impedes translocation. Within the bean plant, translocation is impeded at low temperatures but rises to a maximum betwecn $68 \mathrm{~F}$ and $86 \mathrm{~F}(20-30 \mathrm{C})$, but decreases at still higher temperatures (Bonner and Galston, 1952).

Relatively little work was found relating the influence of temperature to herbicidal effectiveness in the control of mesquite. Tschirley and Hull (1959) report that air temperature, relative humidity, and soil temperature at a depth of 10 inches $(25 \mathrm{~cm})$ did not significantly influence herbicidal effectiveness on velvet mesquite.

One would expect that shaded sites, low sites holding extra water, and clay sites would be relatively cool sites, but one characteristic often overlooked that can affect soil temperature is $\mathrm{CaCO}_{3}$ content of soils. As far back as 1935, Rubel suggested that a physically light (or sandy) soil could be replaced as far as plants are concerned by a clay soil containing lime. He pointed out that the 2-valenced calcium ion brings about coagulation in the solid dispersion of a heavy clay soil effecting a change to a coarser state which could then physically behave more like a loam. Billings (1952) points out that limestone often allows certain species to extend farther than normal into cold or wet climates. For instance, he reports that Shreve found that southern Arizona desert species such as ocotillo and creosote bush reach their upper limits from 900 to 1500 feet higher on limestone soils than on granite soils. Also in the Great Basin, pinyon pine extends farther north and to higher elevations on soils derived from limestones and other rocks rich in calcium. This is generally interpreted to indicate that calcium imparts a more xeric characteristic to the site. However, lack of heat (or lack of cold tolerance) also probably is partially limiting the northern distribution of pinyon pine, ocotillo, etc. If calcium imparts the traits of a coarser textured soil to fine textured soils, then soils high in calcium should be warmer soils, partially accounting for the increased northerly distribution on such soils.

Fisher et al. (1956) like the Arizona researchers, reported no particular influence from humidity on herbicidal effectiveness in aerial applications on honey mesquite. However, it does have an influence on evaporation rates and may affect the entry of herbicides into a plant so its importance should not be discounted.

\section{Methods}

The study areas are on the Post-Montgomery (UU) Ranch near Post, Texas, in Garza and Lynn Counties. Fourteen sites varying in topography, soil type, and exposure were selected for study. Soil series ranged from Lincoln sand on a sandy bottomland site to an Arch clay loam on a deep harland site. Soil moisture electrical resistance cells were installed in all selected sites. Units were buried at $6,12,18,24,36$, and 48 inches. Moisture and tempcrature readings were made from these buried units with a specially constructed ohm meter.

During 1968, 2,4,5-T was applied to honey mesquite trees on all study sites on four different dates. Treatment dates were: June 11-13; July 2-5; August 29-September 4; and October 11-22, 1968.

Five trees per site were individually sprayed at each treatment date. A $3 \frac{1}{2}$ gal garden compressed air sprayer was used to apply the herbicide. Treated trees were no taller than $8 \mathrm{ft}$ because larger trees could not be sprayed with the available apparatus. Manufacturer's recommendations were followed for the spray mixture. Basically it was one oz of Esteron (2,4,5-T, $4 \mathrm{lb}$. A.E./gal) dissolved in an oz of diesel oil and water added to make one gal (or $3 \mathrm{lbs}$. $2,4,5-\mathrm{T}$ ester $/ 100$ gal water). A $0.1 \%$ of surfactant (Trade name Tryad) was included.

Phenological development was recorded for each tree treated. Air temperature, relative humidity, wind speed and direction and soil temperatures were recorded at the time of treatment. Gravimetric soil moisture samples were taken at 6-inch depth increments to a depth of $4 \mathrm{ft}$ to accompany the electrical resistance readings. Also, depth to effervescence with $10 \% \mathrm{HCl}$ and depth to a definite $\mathrm{CaCO}_{3}$ layer were recorded. Trees were checked for root kill in October, 1969, following the second growing season.

\section{Results}

Our first 2,4,5-T applications were made about 60 days after the first leaves appeared and shortly after they changed from light to dark green; i.e. the time assumed to be optimum for mesquite root kills in our area. To find out the kind of response that might be obtained during less than optimum conditions, other trees were sprayed on each site in July, August, and October. For top kills application date was much less important 
Table 1. Mesquite root kills (\%) from 2,4,5-T by site and application date.

\begin{tabular}{lrrrr}
\hline \hline Effect on plants & June & July & Aug. & Oct. \\
\hline Dead & 35 & 40 & 5 & 10 \\
$\quad$ Sandy soils & 60 & 60 & 0 & 20 \\
$\quad$ South slopes & 0 & 0 & 0 & 0 \\
$\quad$ North slopes & 20 & 10 & 20 & 0 \\
$\quad$ Bottom & 0 & 0 & 0 & 0 \\
Bottom sites (not sandy) & 20 & 0 & 0 & 0 \\
Clay loam site & 20 & 7 & 0 & 0 \\
Shallow sites & 0 & 20 & 0 & 0 \\
$\quad$ Potter & 30 & 0 & 0 & 0 \\
$\quad 15$ & 15 & 10 & 10 \\
$\quad$ Other & 20 & 17 & 4 & 6 \\
Altermediate sites & & & & \\
Sprouts & 49 & 63 & 12 & 1 \\
Basal sprouts only & 27 & 20 & 83 & 26 \\
$\quad$ Basal and stem sprouts & 4 & 0 & 1 & 67 \\
Healthy & & & & \\
\hline
\end{tabular}

Table 2. Correlation coefficients ${ }^{\mathrm{a}}$ ( $\left.r\right)$ relating plant root kill to various environmental measurements for the June and July herbicide treatments.

\begin{tabular}{|c|c|c|}
\hline Environmental measurements & June & July \\
\hline Soil Temperature $18^{\prime \prime}$ & $.715(1)^{\mathrm{b}}$ & $.483(3)^{\mathrm{b}}$ \\
\hline \multicolumn{3}{|l|}{ Phenological development } \\
\hline Soil Temperature $36^{\prime \prime}$ & $.550(3)$ & $.430(6)$ \\
\hline Time of Day & $-.426(4)$ & $-.195(21)$ \\
\hline Soil Texture (wi & $-.392(5)$ & $-.561(1)$ \\
\hline Soil Temperature $24^{\prime \prime}$ & $.349(6)$ & $.467(4)$ \\
\hline Water as $\%$ of the 30 & $.324(7)$ & $.113(26)$ \\
\hline \multicolumn{3}{|l|}{ Depth to effervescence with } \\
\hline $10 \% \mathrm{HC}$ & $-.314(8)$ & $-.451(5)$ \\
\hline oil 'Te & .291 & $.348(8)$ \\
\hline y & .241 & $.178(23)$ \\
\hline Avaslable W & $-.239(11)$ & $.206(18)$ \\
\hline$\%$ & $.190(12)$ & $.086(27)$ \\
\hline Available & $.141(13)$ & $.135(25)$ \\
\hline Air Ter & $-.107(14)$ & $-.032(28)$ \\
\hline oil T & $-.090(15)$ & $.296(11)$ \\
\hline Acc & $-.087(16)$ & $.343(9)$ \\
\hline to $\mathrm{CaCO}_{3}$ la & $.078(17)$ & $.219(17)$ \\
\hline Available water $31-36^{\prime \prime}$ & $-.073(18)$ & $.189(22)$ \\
\hline & $.065(19)$ & $.352(7)$ \\
\hline 31 & .065 & $.196(20)$ \\
\hline Ac & -.053 & $.311(10)$ \\
\hline & .035 & $.196(20)$ \\
\hline Accur & $.022(22)$ & $.253(13)$ \\
\hline Avail & $.018(23)$ & $.136(24)$ \\
\hline Acc & .017 & $.229(16)$ \\
\hline Acct & $.014(25)$ & $.256(12)$ \\
\hline ated available water $36^{\prime \prime}$ & $.006(26)$ & $.243(14)$ \\
\hline Accumulated available water $42^{\prime \prime}$ & $.005(27)$ & $.235(15)$ \\
\hline Available water $37-42^{\prime \prime}$ & $.000(28)$ & $.204(19)$ \\
\hline
\end{tabular}

a Coefficients (r) have to be .532 or greater to be significant at the $5 \%$ level.

${ }^{b}$ Rank or order of importance. than for killing mesquite roots. Top kills were 96, 100 , 99, and $33 \%$, respectively, for the June, July, August, and October applications. Sprouts were almost entirely basal from June and early July treated trees, but sprouts following August and October applications occurred the full length of the branches. Following the October application sprouts were so profuse that $67 \%$ of the plants were ratcd healthy in 1969 (Table 1).

Soil temperature at the 18 inch depth proved to be the site characteristic best correlated to mesquite kill with 2,4,5-T in this study (Table 2). Chemical researchers in Texas have consistently indicated that the more mesic bottom sites and clay soil sites allow poorer mesquite kills with 2,4,5-T than the more xeric upland and sandier soils (Fisher et al., 1959). This has been an apparent contradiction as most researchers working with growth regulating herbicides have found good moisture conditions at the time of herbicide application to enhance plant kills (Fisher et al., 1956). Despite the limited extent of our study, the finding that soil temperatures in some way accounts for these variations in herbicide response due to soil type offers at least a partial clue as to why mesquite kills respond differently on different sites.

The roots of mesquite trees growing on warmer sandy soils were more easily killed than trees growing on any other site regardless of topographic position. The roots of trees growing in cool sites, such as densely shaded bottom or lowland sites and soils with a high proportion of clay, were very difficult to kill with 2,4,5-T. Indications were that soil temperatures 18 inches deep should be at least $75 \mathrm{~F}$ and preferably over $80 \mathrm{~F}$ for best results (Fig. 1). When soil temperatures were in the 60's

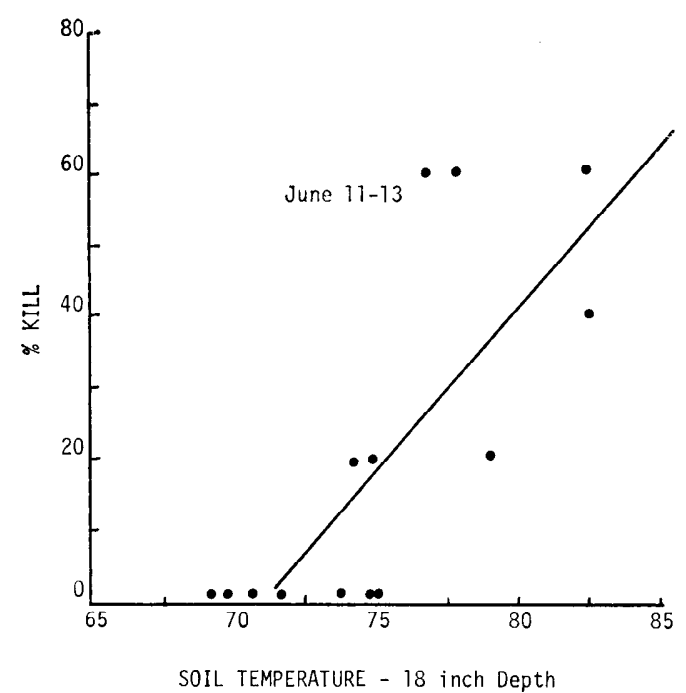

Fig. 1. Relationship of soil temperatures at the 18 inch depth to Mesquite kills with 2,4,5-T. 
or low 70's, 2,4,5-T applications were ineffective except for top kills.

For both the June and early July applications, soil temperatures at the 18 inch depth varied as much as $13 \mathrm{~F}$ from the coolest to the warmest site. The clay loam site was 8 and $7 \mathrm{~F}$ cooler, respectively, for these two months than the warmest soils. Because bottom sites and clay soils normally have more total water than other kinds of sites and because water has a high specific heat, these sites will always be relatively cooler. More dense mesquite thickets are also common on these sites providing shade for greater cooling than occurs under an average canopy cover. If it is indeed true that sugar consumption or other metabolic functions are slowed with cool temperatures (Bonner and Galston, 1952; Muzik, 1967) resulting in less translocation to the root, then the apparent paradox concerning the poor response of plants to herbicides on the wetter sites becomes more logically explained.

In addition to soil texture, slope direction, topographic position, and density of vegetation, $\mathrm{CaCO}_{3}$ is known to be a factor at least indirectly contributing to soil temperatures. Billings (1952) indicates that limestone soils can allow plants to grow in colder and wetter sites than they normally occupy. We also found that some sites were warmer than expected and some colder apparently becausc of the presence or absence of $\mathrm{CaCO}_{3}$. In one case, a relatively wet bottomland site, normally expected to be a cool site, had sufficient $\mathrm{CaCO}_{3}$ content to effervesce with $10 \% \mathrm{HCl}$ throughout the soil profile. It was as warm at 18 inches as the normally warmer upland sites. In other cases, $\mathrm{CaCO}_{3}$ content was confounded with slope direction and it is unlikely that we can separate the two; e.g. no mesquite root kill was obtained on a sandy upland, north slope site that was $7 \mathrm{~F}$ cooler than a similar south facing site that had $60 \%$ mortality with $2,4,5-\mathrm{T}$. The south slope sandy site was calcareous, but the north slope was not. While sufficient $\mathrm{CaCO}_{3}$ to effervesce with $10 \%$ $\mathrm{HCl}$ appeared to contribute to a favorable combination of factors necessary for mesquite mortality, we obtained no significant correlation with it by itself and mesquite mortality.

Other studies now underway indicate that soil temperatures may, in large part, dictate relative development of mesquite reproductive organs among sites. If so, soil temperature and growth stage would largely be but different expressions of the same characteristic as far as susceptibility to 2,4,5-T is concerned. Next to soil temperature, stage of development was best correlated to mesquite root kills for this study. Mesquite plants appeared susceptible to 2,4,5- $\mathrm{T}$ in the order listed in Table 3. Root kills with $2,4,5-\mathrm{T}$ were hardest

Table 3. Stage of growth ranked according to apparent susceptibility to $2,4,5-T$.

Growth stage Number rating

Only young blooms

All ages of flowers

Wilted flowers only

No flowers at all

All ages of flowers plus pods

Young blooms plus wilted flowers plus pods

Young blooms plus minute flower spikes

Young blooms plus wilted flowers

Minute spikes only

Minute spikes plus pods

Wilted flowers plus pods

Pods only

1

1

2

2

4

5

5

5

6

8

10

10

to obtain from trees with young blooms and those totally without reproductive parts. Also, trees with any floral combinations that included young blooms were relatively hard to kill. Conversely, mesquite roots were easiest to kill when the plants had seed pods and plants with floral combinations that included pods were relatively easier to kill than those without pods. Chi Square statistical analyses were used to verify these conclusions. Also, these conditions seem to closely approximate the optimum stage of development for best kills of velvet mesquite with 2,4,5-T in Arizona (Tschirley and Hull, 1959).

If young, non-blooming, flower spikes were small, they apparently did not alter the downward flow of carbohydrates as much as the larger spikes that were blooming. Therefore, until food storage studies can be made, we assume that blooming mesquite plants import foodstuffs from other plant organs, thus at least partially inhibiting translocation to the roots. The reverse should be true for plants with pods. Similarly, Muzik (1967) found that Amsinckia intermedia responded markedly less to 2,4-D when it began to flower. Therefore, if our ability to relate carbohydrates translocation patterns to stage of growth were more precise, we think that phenological development would be equally as good or probably a better character determining degree of mesquite mortality from 2,4,5-T than soil temperature.

Contrary to expectations, air temperature and relative humidity were poorly related to plant root kills with 2,4,5-T in this study. Root kills were somewhat better related to time of day, at least in the June applications, although not significantly so (Table 2). That is, the earlier in the day the chemical was applied, the better the plant kill. One would normally assume this would be due to the lower early morning temperatures and higher relative humidity, but our data gave no indication that such a relationship existed. Appar- 
Table 4. Step-wise multiple regression values important to 2,4,5-T kills of mesquite roots.

\begin{tabular}{cccc}
\hline \hline & & \multicolumn{2}{c}{ Multiple regression } \\
\cline { 3 - 4 } Step No. & \multicolumn{1}{c}{ Variable entered } & $\mathbf{R}$ & $\mathbf{R}^{2}$ \\
\hline June applications & & \\
1 & Soil temperature 18" & .72 & .52 \\
2 & Phenological development & .81 & .66 \\
3 & Available water 37-42" depth & .90 & .81 \\
4 & Available water 7-12" & .95 & .90 \\
5 & Depth of CaCO in inches $^{\prime \prime}$ & .97 & .94 \\
6 & Wilting coefficient (soil texture) & .98 & .96 \\
July applications & & \\
1 & Soil texture (wilting coefficient) & .56 & .31 \\
2 & Soil temperature 6" & .67 & .45 \\
3 & Available water 13-18" depth & .76 & .58 \\
4 & Accumulative water in 24" & .85 & .72 \\
5 & Soil temperature 24" & .92 & .85 \\
6 & Available water 31-36" depth & .93 & .86 \\
7 & Phenological development & & \\
& (stage of growth) & .95 & .90 \\
\hline
\end{tabular}

ently within the air temperature and relative humidity limits of our study, other factors influencing plant growth, translocation and accumulation of carbohydrate reserves were more influential. Also, we could find little relationship between soil moisture and mesquite root kills (Iable 2). However, the soil was not extremely dry on any site for any date during this 1968 study.

The ability to accurately predict percent root kill of mesquite following 2,4,5- $\mathrm{T}$ application has been, and will undoubtedly remain, an elusive skill because of the large number of variables that may alter the results. Nevertheless, the values in Table 4 indicate that plant kills with 2,4,5-T may be accurately predicted because almost all of the factors affecting plant response are accounted for if one can believe the $R^{2}$ values, i.e. a $R^{2}$ value of 1.00 would indicate that all of the variables affecting root kill are accounted for. Despite the desire to predict an actual root kill, most people working in mesquite control are satisfied if they know the requisites for a good kill. They can then pick the timc best suited for them within this framework. If one were to choose a prediction equation, he would ideally use variables that are rapidly measured in the field. The values below may all be field measured within about a 10 minute period, thus, they may be preferred to those that could be developed from the variables in Table 4 which may be more accurate, but could not all be quickly obtained in the field.

For early June (optimum spraying period):

Estimated $\%$ root kill $=-197+1.30$ (phenological development for 5 trees) +3.43 (Temp. (a) 18-inch depth) -0.04 (Time of day) -0.37 (relative humidity).
For early July conditions (past optimum):

Estimated root kill $=-19.64+1.20$ (phenological development for 5 trees $)+0.87$ (\% relative humidity) -0.97 (depth to effer. with $10 \% \mathrm{HCl}$ ) -0.002 (mean of soil temp. for $12+18+24$ inch depths). 2

Multiple correlation coefficient $(R)$ for the June and July periods are 0.84 and 0.80 , respectively.

\section{Discussion and Conclusions}

Findings from this study agrce in gencral with those of other mesquite control research in Texas and Arizona concerning the importance of correct time of application and the site characteristics needed to obtain acceptable mesquite root kills with 2,4,5-T. Our study indicates that soil temperature was the single most important factor affecting response of honey mesquite to 2,4,5-T application. However, little literature was found relating the influence of soil temperature to herbicidal effectiveness in the control of mesquite. In fact, only one field study has been found to date. Tschirley and Hull (1959) report that air temperature, relative humidity and soil temperature at a depth of 10 inches $(25 \mathrm{~cm})$ did not significantly influence herbicidal effectiveness on velvet mesquite. Although they measured soil temperature it was at only the 10 inch depth which was found to be non related. Likewise our 6 (15 $\mathrm{cm})$ and $12(30 \mathrm{~cm})$ inch depth temperature measurements indicated no relationship to herbicidal effectiveness; but, when we used the 18 inch (46 $\mathrm{cm}$ ) depth soil temperature, we found a close relationship between increasing temperature and 2,4,5-T effectiveness for the range of temperatures included. We assume this response is due to difference in rate, quantity, and quality of movement of foodstuffs within the plants as affected by soil temperatures. Janick et al. (1969) report that high soil temperatures are needed for optimum cell division or meristematic activity. We also know that certain B-vitamins are needed for root growth which are produced in the leaves and that low temperatures applied to local areas on plant stems greatly impedes translocation (Bonner and Galston, 1952). Therefore it seems logical that if herbicide translocation is related to B-vitamin translocation as found by Muzik (1967) and carbohydrate translocation as indicated by Crafts (1953), then both soil temperatures and the lower stem temperatures should be tremendously important in herbicide translocation to the roots. We have not measured the stem temperatures to verify this, however.

Both Texas and Arizona researchers agree that stage of growth is the best single criterion for determining maximum susceptibility of mesquite to foliage sprays. Despite the first place ranking of soil temperature in our study, we believe that phenological development would have been as 
important, if not more so, if wc had a better knowledge of how to quantify stage of growth. As it is, it is our second best measurement of susceptibility to 2,4,5-T. Tschirley and Hull (1959) felt that leaf maturity was more important than flower development in gauging vclvet mesquite susceptibility to $2,4,5-\mathrm{T}$ but once honey mesquite leaves have become mature, i.e., turned dark green, degree of flower and fruit development are the only usable guides remaining for determining stage of growth as a guide to herbicide susceptibility. Most all studies of carbohydrate storage in plants indicate that storage organs are more rapidly recharged following reproduction, and that recharge is considerably slowed, if not stopped, during flowering. Likewise, our study revealed that honey mesquite trees with young and blooming spikes and those without flowers or pods were hardest to kill and mesquite plants with pods were easiest to kill.

Other environmental measurements thought important during this study, such as soil moisture, air temperature, relative humidity, and time of day were not significantly correlated to mesquite root kills as individual measurements. However, we assume they are very important in combination as each are known to affect the physiological processes within all plants and anything that affects the physiological processes at least indirectly affects the movement within the plant of growth regulating herbicides. As indicated in Table 4, the proper combinations of variables can apparently account for most variation affecting mesquite root kills. During optimum spraying conditions, soil temperatures and phenological stage of development apparently account for two-thirds of the variation affecting mesquite plant kills. Soil texture, topographic position, and degree of shade are the physical environmental traits that combine to provide the conditions necessary for variation in these two traits. Our current challenge is to find ways to overcome the unfavorable soil temperatures that usually prevail on bottom sites, clay soils and densely shaded sites during the optimum spraying season.

\section{Literature Cited}

Barrier, George E., and W. E. Loomis. 1957. Absorption and translocation of 2,4-dichlorophonoxyacetic acid and P32 by leaves. Plant Physiol. 32:225-231.
Basler, Eddie, Glenn W. Todd, and Raymond E. Meyer. 1961. Effects of moisture stress on absorption, translocation, and distribution of 2,4-dichlorophenoxyacetic acid in bean plants. Plant Physiol. 36:573-576.

Billings, W. D. 1952. The environmental complex in relation to plant growth and distribution. Quart. Rev. Biol. 27:251-265.

Bonner, James, and Arthur W. Galston. 1952. Principles of Plant Physiology. W. H. Freeman and Co., San Francisco. 498 p.

Cox, D. K. 1952. Effect of soil moisture on reaction of velvet mesquite to topical application of selective hormone type herbicides. Western Weed Control Conf. Res. Prog. Report 13:50.

Crafts, A. S. 1953. Herbicides. Their absorption and translocation. Agr. and Food Chem. 1:51-55.

Fisher, C. E., C. H. Meadors, and R. Behrens. 1956. Some factors that influence the effectiveness of 2,4,5tricholrophenoxyacetic acid in killing mesquite. Weeds 4:139-147.

Fishfr, C. E., C. H. Meadors, R. Bfhrens, F. D. RobbinSON, P. T. Marion, AND H. L. Morton. 1959. Control of mesquite on grazing lands. Texas Agr. Expt. Sta. Bull. 935. 24 p.

Freed, V. H., AND R. O. Morris. (Editors). 1967. Environmental and other factors in the response of plants to herbicides. Oregon Agr. Exp. Sta. Tech. Bull. 100. $128 \mathrm{p}$.

Janick, Jules, Robert W. Schery, Frank W. Woods, and Vernon W. Ruttan. 1969. Plant science-an introduction to world crops. W. H. Freeman and Company, San Francisco. $629 \mathrm{p}$.

Muzik, T. J. 1967. The influence of environment on the response of plants to certain herbicides. In Environmental and other factors in the response of plants to herbicides. V. H. Freed and R. O. Morris, editors. Oregon Agr. Exp. Sta. Tech. Bull. 100:63-73.

Robison, E. D., C. E. Fisher, and B. T. Cross. 1970. Control of mesquite and associated west Texas brush with 2,4,5-T/Picloram combinations. Proceedings 23rd Ann. Meet. S. Weed Sci. Soc. Atlanta, Ga.

Rubel, E. 1935. The replaceability of ecological factors and the law of the minimum. Ecology 16:336-341.

Tingey, D. C., L. C. Erickson, and H. P. Cords. 1967. The influence of soils, moisture, and fertility on the response of plants to foliar-applied herbicides. In Environmental and other factors in the response of plants to herbicides. V. H. Freed and R. O. Morris, editors. Oregon Agr. Exp. Sta. Tech. Bull. 100:75-88.

Tschirley, Fred H., and Herbert M. Hull. 1959. Susceptibility of velvet mesquite to an amine and ester of 2,4,5- $\mathbf{T}$ as related to various biological and meterological factors. Weeds 7:427-435.

\section{Specialists in Quality NATIVE GRASSES Wheatgrasses • Bluestems - Gramas • Switchgrasses • Lovegrasses • Buffalo • and Many Others We grow, harvest, process these seeds

